\title{
A Study of Chinese Learning of English Tag Questions
}

\author{
Qiyun Zhang \\ Foreign Language College of Tianjin Polytechnic University, Tianjin, China \\ Email: zqydisk@eyou.com
}

\begin{abstract}
Questioning or being questioned is a necessity in communicative activities. The tag question plays an important role in everyday communication. In the tag mechanism of those questions, the tags are not formed in accordance with the general forming rules. So, learners often commit errors. This paper studies the types and causes of errors of the tag question. By analyzing these error sources, the learner can avoid and benefit from errors. Thus, they can understand tag questions better.
\end{abstract}

Index Terms - tag question error, learn, second language acquisition

\section{INTRODUCTION}

The tag question, as a kind of interrogation, is rather complicated in the semantic aspect. And due to the informality of the colloquial English, the patterns appear, more often than not, to be irregular. The first part of this paper is the generalization of the English tag question. When the tag question produced by we Chinese people are examined and compared with target language norms, they are often found to be full of errors. The second part of this essay attempts to analyze every kind of causes of errors. There are five error sources--Negative transfer of the mother tongue; Overgeneralization of the formation rule; Ignorance of rule restrictions; Incomplete application of rules; False concepts hypothesized(Xu Jie,2008:37).As errors are inevitable, they are an integral part of language acquisition. We should try to seek methods to avoid committing errors repeatedly and continuously. The latter part of this article is to deal with three kinds of approaches of avoiding and benefiting from these errors. They are --Compare tag questions in both languages; Increase target language input and output; Effective feedback to learner errors (Xu Jie, 2008).

\section{LITERARY REVIEW}

In the 1950s and 1960s, a favored paradigm for studying second language learning and organizing its teaching was Contrastive Analysis. Contrastive Linguistics can be defined as a sub discipline of determine both differences and similarities between them. Johansson and Hofland held that language comparison is of great interest and can be categorized in a theoretical as well as an applied perspective. Therefore, the study may be theoretical, without any immediate applications or may be applied, namely, carried out for a specific purpose (Xu Jie, 2008).

But, in 1973, many examples made by Dulay and Burt showed that $85 \%$ of the errors of second language acquisition were "developmental" (i.e., on-interference errors), $12 \%$ were unique and only $3 \%$ were result of L1 interference. Under this circumstance, Wardhangh (1970) proposed a distinction between the strong and the weak version of CA. The latter became known as error analysis (quoted by Xu Jie, 2008). It can be further divided into four categories: 1) Overgeneralization.2) Ignorance of rule restriction.3) Incomplete application of rules.4) False concepts hypothesized (Xu Jie, 2008).

This paper attempts to apply these error theories to English tag questions learning. By analyzing the specific errors theoretically and systematically, Chinese learners can benefit from them.

\section{Generalization of TAg Questions}

The tag question, one of the important English sentence patterns of speech plays a great important role in people's communication. It mainly consists of "declarative sentence plus tag question ".The declarative sentence is used to put forward a view of the speaker, while the tag question indicates this view wants to be identified.

The tag question can be classified into two categories. One is the canonical tag question, the other the invariant tag question (Yang Shideng, 2006).The canonical tag question is much more complicated. People should consider gender, number, and tense into account in order to meet grammatical needs. That is to say, the function word of the tag question should agree with the predicate verb in the preceding declarative sentence or the functional word in number, tense and form. The invariant tag question uses modal words to interrogate, such as "right", "yeah". This kind of modal words are invariant. The invariant tag question is less formal than the canonical tag question. It is very colloquial. The following are the examples of this kind:

You can play basketball, right? (invariant tag question) 
You are almost fluent in English, yeah? (invariant tag question)

The canonical tag question can be further divided into non-disjunctive question and disjunctive question. Non-disjunctive question refers to tag question which the declarative part and the tag question are either negative or affirmative. e.g.

Open the window, will you?(non-disjunctive tag question)

The cat is in the house, isn't it? (disjunctive tag question)

The disjunctive tag question refers to tag question which the declarative part and the tag question are either negative or affirmative. It can be categorized into regular question tags and irregular question tags. The irregular question tags are the exceptions which did not comply with the formation rules of tag question. e.g.

He often plays basketball, doesn't he? (regular tag question)

Nobody went to the library, did they? (irregular tag question)

\section{ERRORS MADE BY CHINESE LEARNERS}

An error, in its technical sense, is the breaches of rules of code; it is the noticeable deviation grammaticality resulting from a lack of requisite knowledge. It arises because of the lack of competence. According to James's definition, an error is an "instance of language that is unintentionally deviant (unlike poetry) and is not self-corrigible by its author"'(Xu Jie,2008:37). That is to say, error refers to a deviation from the acceptable target language that the learners did not recognize or do not know how to correct.

As a saying goes, "To err is human". Errors are seen as a natural phenomenon that must occur when learning the first or second language. I $t$ is an integral part of human learning. So, when people learn English tag question, they inevitably commit errors. As errors are normal things, we should study the causes leading to the errors. The next below are the types of errors and errors sources.

\section{A. Negative Transfer of the Mother Tongue}

Lado in his influential book Linguistics Across Culture claimed: "Individuals tend to transfer the forms and meanings and the distribution of forms and meanings of their native language and culture to the foreign language and culture---both productively when attempting to grasp and understand the language and the culture as practiced by natives"(Ning Guo,2005:16).Simply, transfer can be defined as "the influence resulting from similarities and differences between the target language and any other language that has been previously acquired "(Ning Guo,2005:17).It can be positive or negative. When the language patterns of L1 and L2 are identical, learning could take place easily through positive transfer of the L1 pattern, but when they are different, learning would be difficult and errors may arise as the result of negative transfer or interference.

So, in the case of negative transfer, many elements of the native language have no corresponding counterparts in the target language,L1 habits would cause errors in the L2 and learners would transfer inappropriate properties of L1.It is true for English tag question learning.

In Chinese, we also use some phases like “是不是”, “好吧”, “是吧”, “对吧”to interrogate. The Chinese tag question can be seen as a kind of invariant tag question. People need not to consider questions related with agreement. This habit can lead to the fact that Chinese learners rely much on the invariant tag question and neglect the canonical ones. Because the Chinese phases“是吧”, “对吧”can be translated to “right” “okay” in English. Here are the examples:

她妈妈病了, 对吧?

Her mother was ill, right?

In the above English tag question, people will use "right" rather than "hasn't he". This phenomenon can be regarded as a kind of negative transfer.

Due to this kind of negative transfer, people use more invariant tag questions than the canonical ones. So, when communicating with others who often use the canonical tag questions, they usually misunderstand them and commit errors of comprehension.

\section{B. Overgeneralization of the Formation Rule}

Overgeneralization covers the instances where the learners create a deviant structure on the basis of his experience of other structures of the target language. It is learners' previous knowledge of the second language that learners use. That is to say, It is the incorrect application of previously learned second language material to a present second language context. It is one of the common causes of language errors. For example:

Everybody is here, isn't everybody? (aren't they?)

You had your hair cut last night, hadn't you? (didn't you?)

The above examples show that there are some exceptions of the tag question rule. The learners can't treat it in the same way.

\section{Ignorance of Rule Restrictions}

This type of errors is again a type of generalization or transfer. Since the learner is making use of a previously acquired rule in a new situation, some rule restriction errors may be caused by analogy (YAN Lidong, 2004:83).For 
example:

I didn't expect that she would give up the opportunity, did I?(would she?)

I suppose Lucy's crying, don't I?(isn't she?)

When learners encounter a complex sentence, they attempt by analogy to follow the same rule. Thus errors were committed.

\section{Incomplete Application of Rules}

In order to produce some sentence structures, more than one rule should be used or a rule is used to some different degrees. But learners sometimes fail to understand or apply these rules completely. For example:

She hardly plays with you, doesn't she? (does she)

I never said she was wrong, didn't I? (did I)

The learner knows the agreement rule of forming an English tag question. But when there are some words which denote negative without the word "not", the learner has some difficulties in dealing with the whole sentence. Thus he produces the above sentences in stead of correct ones.

\section{E. False Concepts Hypothesized}

This type of errors means that learners fail to comprehend fully. It derives from faulty comprehension of distinction in the target language. For example:

Lily didn't go to Beijing, did she?

Yes, (she did)

No,(she didn't)

When dealing with the answer, people are usually in a mess and understand the meaning in an opposite way. They may just consider the apparent meanings of the words "yes", "no" without thinking their specific meaning in tag questions.

Another example is about my friend Lucy. She is a tour guide. About five months ago, she guided some foreigners to visit Hangzhou. After finished visiting the scenic spots, there still had time. So, she advised to go to the zoo to see the peacock. The foreigners were excited when hearing her suggestions. But when they arrived at the zoo, they were informed that the peacock was lent to others. My friend was sorry for that and explained the new notice of the zoo. At that time, a woman asked my friend "so, you didn't know that beforehand, did you?" My friend answered "yes". The woman continued asking "You didn't mean that you knew it in advance, did you?" unfortunately, my friend answered "Yes, Miss". The woman was very angry and had sued her.

It is estimated that my friend had known the woman's questions, but she misunderstood the specific meaning of the words "yes", "no" in English tag questions. Thus, the error was committed. This is the error caused by false concepts hypothesized.

So, when one learns English tag questions, one should understand the structures and meanings of them exactly for fear of hypothesizing false concepts.

\section{METHODS TO AVOID ERRORS}

As a saying goes, "A fall into the fit, a gain in one's wit". Since errors are a natural and indispensable part of the learning process, we should try to seek measures to avoid errors or benefit from the previous errors.

\section{A. Compare Tag Questions in both Languages}

Researchers from the 1940s to the 1960s conducted contrastive analyzes (CA), systematically comparing two languages. The proponents of CA assumed that "Where L1 and L2 rules are in conflict, errors are likely to occur which are the result of interference between the two language" (Xu Jie, 2008:36).

So, from this speaking, effective learning of English tag question should be based on scientific perception of the English tag question rules on the one hand, and on appropriate generalization of the Chinese rules on the other. Learners should build up their target knowledge on the basis of the differences between L1and L2 through comparisons of enormous details of two languages. That is to say, when learning English tag question, we should compare the English tag question with the Chinese ones first and try to seek differences between them. For example:

1).A: She has gone to Beijing, hasn't she? 她去北京了, 不是吗?

B: Yes, she has. 是, 她去北京了。

No, she hasn't 不, 她没有去北京。

2).A: She hasn’t gone to Beijing, has she? 她没有去北京, 是吧?

B: Yes, she has. 不, 她去北京了。

No, she hasn't. 是, 她没有去北京。

For the two examples above, the first example of the English tag question is nearly the same with the Chinese one. The learner can learn it easily and quickly. It can be seen as a kind of positive transfer. But the second example shows the other way. The meaning of the words "yes", "no" take on opposite meanings, which are different from our Chinese tag question. That is to say, the Chinese and English answers to tag questions imply meanings respectively. So, through 
this comparison, the learner can pay much attention to the differences and errors were avoided.

\section{B. Increase Target Language Input and Output}

Reading and listening in the SLA situation is understood as the appropriate input for acquisition of language skills. Extensive reading and listening of authentic materials and wide exposure to meaningful and authentic target language contexts might provide input of linguistic knowledge at various levels, lexical, syntactic and even rhetorical and cultural to L2 learners (Xu Jie,2008).

While being exposed to huge amounts of authentic target language input, learners should also be provided with ample opportunities to use and promote target language output. Producing the target language can provide the learners the opportunity to test out hypotheses about the target language and to move from a purely semantic analysis of the target to a more general understanding of it (Xu Jie, 2008).

The increase of target language input and output can resist the interference of the Chinese language. Through a mount of reading, listening and speaking, the learner can acquire the target language accurately. It is true for English tag question learning.

By listening and reading some authentic materials, the learners are likely to produce the tag question smoothly. They will not just depend on the invariant tag question, but focus their attention on the canonical one. When the learner attached more attention on the canonical tag question, errors could be decreased.

\section{Effective Feedback to Learner Errors}

This method is suitable for the students' learning. It is about teachers and students. Teachers play an important role in students' learning. They are supposed to provide adaptive, qualified and motivating support for the individual learner in his learning process. It is important for teachers to be aware of the basis position that errors should neither be tolerated nor corrected excessively.

Some teachers in order to avoid discouraging students always let errors go uncorrected and to indicate understanding when understanding may not have occurred. But unfortunately, their goodwill may result in the reinforcement of the learners' errors and even the persistence and perhaps the eventual fossilization, of such errors. And the influence may even reach other students, for if they regard an un-corrected mistake to be true, they will employ it themselves. (ZHA Ye-juan, 2007:36).

On the other hand, it has been improved that rigid and immediate correction of every error at the time may interfere with and alter learners' path of thinking and induce severe psychological frustration. In some cases, teachers may note errors and deal with them later. This non-immediate correction can also provide time for the teachers to research efficient and effective practice tasks to drill the learners in the correct forms. Moreover, students are different individuals, teachers should treat them respectively.

So, necessary amount of correction is indispensable for teachers to improve students' language performance.

Meanwhile, the students should be informed of the fact that committing errors is a natural part of language learning process, and every man or woman, young or old, smart or ordinary, has to commit errors while learning a language.

As for teachers, they might as well generalize and summarize these frequently appearing errors and remind students of these errors as often as possible. Repeated warnings of certain mistakes beforehand will even eliminate the chances of committing some of these errors.

Take my own experiences as an example. When I was learning English tag question, my teacher put much emphasis on the exceptions which are not agree with f1ormation rule of tag question and asked me to learn them by heart. After remembering these exceptions, I later came across many kinds of tag questions and I seldom made mistakes.

So, through effective feedback, the students can decrease the chance of committing errors.

\section{CONCLUSION}

To sum up, the tag question is not easy to learn. The learners should not only pay attention to the general rules but also the exceptions. As errors are inevitable, this paper has described the errors in English tag question learning, analyzed their causes and types, and threw some light on the knowledge of second language acquisition and on the correct attitude to errors and error correction. If learners can follow the advices above, they may easily understand the tag questions and use them smoothly.

\section{REFERENCES}

[1] Andrew D. Cohem. (2000). Strategies in Learning and Using a Second Language. Beijing: Foreign Language Teaching and Research Press.

[2] Diane Larsen-Freeman \& Michael H.Long. (2006). An Introduction to Second Language Acquisition Research. Beijing: Foreign Language Teaching and Research Press.

[3] Helen Goodluck. (2000). Language Acquisition: A Linguistic Introduction. Beijing: Foreign Language Teaching and Research Press.

[4] Liu Tianyun. (2004). The role of L1 in second language acquisition. CELEA Journal.

[5] Jean Stilwell Peccei. (2000). Child Language. Beijing: Foreign Language Teaching and Research Press.

[6] Jianjia Zhang. (2005). On General Principles of Second Language Acquisition. Sino-US English Teaching. 
[7] Michael McCarthy. (2007). Issues in Applied Linguistics. Beijing: World Publishing Corporation \& Cambridge: Cambridge University Press.

[8] Ning Guo. (2005). The Role of the Native Language in Second Language Acquisition. Sino-US English Teaching.

[9] Victoria Fromkin, Robert Rodman \& Nina Hyams. (2005). An Introduction To Language. Beijing: Peking University Press.

[10] Vivian Cook. (2000). Second Language Learning and Language Teaching. Beijing: Foreign Language Teaching and Research Press.

[11] Xu jie. (2008). Error theories and second language acquisition. US-China Foreign Language.

[12] Yan Lidong. (2004). Implication for second language learning and language pedagogy by analyzing errors in college students' writings. CELEA Journal.

[13] ZHA Ye-juan \& HONG Yi-ming. (2007). Errors in Language Learning. Sino-US English Teaching.

[14] Ding Yanren .(2007). Second Language Acquisition for English Majors. Shanghai: Foreign Language Education Press.

[15] Chang Jianying. (2004). Tag Questions. Journal of Qinghai Junior Teachers' College (Education Science).

[16] Dong Xiaoqiu. (1998).The pragmatic analysis of invariant tag question. Shan Dong Foreign Language Teaching.

[17] Huang Junjuan. (2007). Research on the three theories of language transfer. The Science Education Article Collects.

[18] Wu Shouhong. (2007).The relationship of second language and foreign language. Elementary English Teaching.

[19] Yang Shideng. (2006). A Study of EFL Learners' Oral Production of Tag Questions. Journal of PLA University of Foreign Languages.

[20] Zou Dongqi. (2007). Research on the irregular construction of English tag question from the functional grammar view. Bilingual Learning.

Qiyun Zhang was born in Hebei, China in 1982. She will receive her M.A. degree in linguistics from Tianjin polytechnic University, China in March, 2011.

She is currently a postgraduate in the School of Foreign Languages, Tianjin polytechnic University, Tianjin, China. Her research interests include psycholinguistics and Second Language Acquisition. 